\title{
Pictorial meaning, language, tradition: notes on image semantic analyses by Kristóf Nyíri
}

\author{
Gábor Szécsi ${ }^{1,2}$
}

Accepted: 3 August 2021 / Published online: 20 August 2021

(C) The Author(s) 2021

\begin{abstract}
The iconic revolution changing the routine of everyday communication is gradually leading to the creation of a linguistic structure that combines visual and verbal tools in both formal and semantic aspects. Computer and mobile applications today enable high-tech imaging that ensures the spread of iconic communication in mundane interactions and the possibility of a creative combination of verbal and iconic codes for language users who navigate in a world of images in an increasingly confident manner. The iconic revolution that accompanies this expansion of new communication technologies thus leads to serious changes in language use, thereby enhancing the transmission of verbal and iconic language to become a key element of mundane communication. This article argues that this turn in communication technology guided the attention of Kristóf Nyíri, an eminent figure in contemporary Hungarian philosophy, to the problem of the relationship between icon, language, and tradition. The aim of the present essay is twofold: to shed light on the relevance of Nyíri's analysis and thoughts on the relationship between tradition and language in the history of communication, and to identify, using Nyíri's model of pictorial meaning as a starting point, the relevant aspects of the conception of technological determinism in answering questions from the philosophy of language and mind.
\end{abstract}

Keywords Tradition - Language $\cdot$ Pictorial communication $\cdot$ Media convergence . Iconic language

Gábor Szécsi

szecsi.gabor@pte.hu; szecsi.gabor@btk.mta.hu

1 Faculty of Cultural Sciences, Education and Regional Development, University of Pécs, Pécs, Hungary

2 Research Centre for the Humanities, Institute of Philosophy, Eötvös Loránd Research Network, Budapest, Hungary 


\section{Introduction}

Investigation on the social, cultural, and psychological processes guiding the use of digital technology sheds new light on the hypothesis that great turns in communication technology can change the structure and content of our thinking. Importantly, this assumption in the history of communication, which provides grounds for technological determinism today, has serious philosophical relevance, by courtesy of authors such as Marshall McLuhan, Harold A. Innis, Walter J. Ong, Eric A. Havelock, Jack Goody, Ian Watt, and many other philosophers and philologists often cited by them, such as Oswald Spengler, Friedrich Nietzsche, Bronislaw Malinowski, Milman Parry, and, to mention but a few Hungarian theorists, Menyhért Palágyi, Béla Balázs, István Hajnal, and József Balogh. This extraordinary list of names would not be complete without one of the key figures of Hungarian contemporary philosophy: Kristóf Nyíri. Today, his views on the philosophy of communication, language, and mind serve as guidelines for many in proving the basic tenets for the above assumption. To follow the line of thought in this direction, Nyíri relies heavily on Ludwig Wittgenstein's writings, whose philosophy of language is deeply influenced by his peculiar interest in a distinctive communication technology. Nyíri, starting out from a few Wittgensteinian questions of the philosophy of language, targets questions in the light of technological determinism such as tradition, private language, or pictorial thinking (Nyíri, 1992, 1996/97, 2003, 2011, 2019). In his works, statements targeting the mental and linguistic effects of the use of communication technology become the subject of philosophical analysis from the perspectives of the philosophy of language and the mind. His works on this topic is especially relevant for understanding the problem of the effect of communication technology on linguistic and mental representation, enabling this question to be investigated at the epistemological level and reinterpreted in a wider, more comprehensive framework. The aim of the present study is to show how Nyíri's concept of tradition influenced the history of communication and to delineate, relying on Nyíri's model for iconic language, the dimensions of technological determinism in the philosophy of language and mind.

\section{Language, tradition, and communication technology}

When studying the history of human culture, it becomes increasingly evident that, when a new type of communication technology becomes predominant, this is always followed by the emergence of a new linguistic and cognitive galaxy. This explains why and how the milestones of the history of human culture such as the appearance of writing, printing, or electronic media could have a significant impact on the structure of the mind and on our image of ourselves and of the world. The acquisition of new communication technologies restructures our inner and our social life, because beyond generating changes in the mental world of an individual, it also serves as a process of the history of culture, contributing to the transformation of the inner 
structure of social interactions and to the modification of our concept of community and tradition.

As Nyíri points out in his book Tradition and Individuality, these turns in communication technology that have shaped our cultural history have radically changed the relationship between humans and culture, and the role of tradition and its conceptual representation (Nyíri, 1992). Nyíri argues that, although following and handing down traditions plays an important role in modern society as well, this role is radically different from that played in premodern societies (Nyíri, 1992). Tradition, he claims, has become an institutionalized and unquestionable form of information transmission, determined by the aspects of understandability and easiness to remember in the world of orality and, as such, plays a key role in preserving knowledge and information that is important for communities. Hence, he calls traditions that exist in the framework of orality and dominant communication technology "essential."

However, in the new communication context created by literacy, the primary role of the ritualized form of creating traditions, where there is no reflection on the act of passing down traditions, might fade and eventually disappear. Primary traditions are gradually taken over by "margin traditions" that evolve in the framework of literacy and that can become the subject of critical reflection, possibly being reconsidered and changed. This is because traditions have their own function in the linguistic and noetic galaxy of literacy as well, for example, in learning processes, but their role is by no means as deterministic as it is in cultures that rely on the oral tradition in information transmission.

However, as Nyíri points out, in the age of electronic communication, new structures evolve for the transmission and reception of knowledge and information without reflection. He calls these secondary traditions. Considering the relation between primary and secondary traditions, Nyíri suggests that we:

distinguish between primary and secondary traditions, and say that secondary traditions contain and convey, in an abbreviated and perhaps emotionally bolstered form, information which could in principle though perhaps only with a loss of convenience, be communicated also in a purely discursive fashion. (Nyíri, 1992, p. 52)

As Nyíri emphasizes, the information mediated in primary traditions

cannot be separated from the way in which it is handed down, or rather it can be thus separated only within a context different in kind from that in which these traditions were originally functioning. (Nyíri, 1992, p. 52)

The new culture of communication relying on sources such as the radio, television, internet, and mobile phones is characterized by a nearing of the semantic and grammatical worlds of orality and literacy, leading to the birth of a new, iconic language. This newly organized linguistic culture, although significantly facilitating the processing of the quick flow of large quantities of information, also somewhat counteracts the process in the sense that it inhibits the instant reflection on the message communicated, reviving certain forms of ritualized information transmission. 
In this process, where electronic communication technologies gradually gain more ground, Nyíri primarily emphasizes the perils leading to the fragmentation of the world view of humans receiving information in such a way, and the vulnerability of a coherent, unified world of knowledge. In his later publications on multimedia communication, however, he calls the attention to the fact that the convergence of communication technologies can make information transmission more effective and faster, thus contributing to the creation of a higher-level cohesion in societies and communities. As he writes,

[m]ultimedia messaging, the synchronous-complementary transmission of speech, text, pictures seems to me be not just a social activity sustaining those very types of human communication that make up genuine communities. (Nyíri, 2003, p. 184)

Nyíri, as is apparent from the above-quoted study, defines the appearance and expansion of new forms of traditions in the light of the renaissance of pictorial communication, pointing out that communication in pictures is more genuinely characteristic of human nature than thinking and communicating with words (Nyíri, 2003, p. 183). He argues that we must return to these basic forms of communication, and in doing so we can rely on multimedia-based electronic devices such as mobile phones capable of sending MMS. This trait makes them an extremely effective tool for communication, as they "combine images and words-words spoken and written" (Nyíri, 2003, p. 183).

Nyíri's views above, just as his model on the transmission of traditions, are motivated by Wittgensteinian sources. He himself suggests this when he talks about Wittgenstein's thoughts on the interaction between oral and pictorial language, and the intertwined nature of their functioning. Nyíri has attempted to show in several of his studies that Wittgenstein's later work contains an early version of the theory of pictorial meaning (Nyíri, 1996/97, 2001, 2002, 2003, 2011, 2019). Wittgenstein, as Nyíri shows, while attributing different logic to oral and pictorial language functions, is also keen to understand the reciprocal relationship of these two logics. Wittgenstein's writings are motivated by the rediscovery of the possibilities of interpretation provided by pictorial language, which, as Nyíri underlines, sometimes brings along blurry definitions of the concept of the primacy of pictorial thinking and of pictorial communication. Nyíri claims that Wittgenstein's attraction to pictures mostly stems from his dissatisfaction with forms of written expression and written contexts.

As Nyíri points out, the problem relating to written language, the preference for orality, is obvious in Wittgenstein's philosophy. One sign of this is the argumentation starting from the negation of the so-called private language, defined as the language that directly expresses the inner mental experiences of the individual. This tenet, known as the "private-language argument," suggests the primacy of a language for communication that gives no possibility of conceptual reflection on the content of the message. Compliance with the rules of language is only possible through a reflection on them, that is, through the conscious awareness of these rules themselves, which, however, in Wittgenstein's view only leads to the illusion of rulefollowing and, therefore, to the birth of a language that is nonintelligible to others. 
Nyíri believes that this Wittgensteinian approach is a sign of the philosopher's preference for orality. Of course, Wittgenstein was never aware of this biased tendency in his writings; at least, we find no reference in his writings to the philosophical significance of the differences between written and spoken language. Indeed, Nyíri claims that Wittgenstein does not really differentiate these two forms of language; his claims concern both written and oral language.

Nyíri claims that this peculiar, not conscious, attraction to the linguistic worlds of primary traditions is due to the special conservative stance apparent in Wittgenstein's writings. As he writes:

Wittgenstein's oral bias, his interest in primitive societies, his authoritarian views on education, his traditionalism, his use-theory of meaning, and his argument against the possibility of a private language together make up a coherent outlook. (Nyíri, 1992, p. 112)

Nyíri, through a close examination of critical writings on Wittgenstein's works, draws conclusions that also enable him to investigate the orality-literacy paradigm in a context of the philosophy of language and mind. This approach is apparent in Nyíri's writings that deal with linguistic and epistemological changes that emerge as a result of the revolution in today's communication. Hence, Nyíri introduces or re-considers several concepts that help us understand not only semantic, conceptual changes typical of electronic communication, but also the linguistic and mental processes brought along by more general, great turns in the technology of communication. Pictorial language belongs to this conceptual domain. In the next section, I elaborate on this concept, which also receives a lot of attention in Nyíri's writings, to reveal the aspects of this issue that are relevant relevant for the philosophy of language and mind.

\section{Pictorial language and convergence of language use}

Nyíri believes that, since electronic media (television, internet, MMS, and text messages (SMS) services on mobile phones) represent a fruitful ground for the combination of pictorial and verbal communication, our everyday exchange of information can become more effective than ever. In the background of this claim, we find the above-mentioned notion that communication in pictures stems from deeper layers of human nature, deeper than oral forms of communication and thinking, because the images "are the primordial stuff of thought" (Nyíri, 2003, p. 157); in other words, images "form the main content of our thoughts" (Nyíri, 2003, p. 158). As Nyíri suggests,

in the course of human phylogeny and ontogeny it was the language of gestures, and not verbal language, which introduced conceptual order into the episodic imagery of pre-linguistic thought. Verbal language, pervaded by metaphor, builds on the meanings and semantic relationships created by the language of gestures. (Nyíri, 2003, p. 157) 
As primordial elements of thought, images are fundamentally related to the world of objects on a similarity basis. The external images show, of course, that this similarity is not imprint-like. There are also many levels of abstractions in the images, which, as Nyíri claims, raises fundamental philosophical questions about the relationship of tradition and pictorial similarity. At the same time, the relationship between images and the order formed by them is also peculiar, spatial, and analogous. The signs, or the inner, mental images, and the things they signify, have the same relationship, a systemic connection: what is similar in the world is similar in our heads.

This view stems from theories of authors such as Price (1953), Arnheim (1969), Paivio (1971), and Gombrich (1972), to which some recent models (Lakoff \& Turner, 1989; Lakoff \& Jonhson, 1999; Abell \& Currie, 1999; Westerhof, 2005; Lakoff, 2008a, 2008b; Kulvicki, 2010) contributed with new perspectives targeting the relation between picture, language, and thought. One of these models is Jan Westerhof's structuralist theory of the logical relations between pictures (Westerhof, 2005). Westerhof argues that such logical operations as conjunctions, disjunctions, and negations of pictures correspond to natural cognitive operations employed when we think about pictures. As Westerhof claims, "these logical operations are closely related to, or may even be identical to basic cognitive operations we naturally employ when we think about pictures" (Westerhof, 2005, p. 605). John Kulvicki puts the problem of the special epistemic place of images in an interesting light, when he argues that we

can reason with images rather than just decoding them and reasoning about their contents, in the sense that perceptual abstractions from their determinate details can lead us to conclusions about their contents. (Kulvicki, 2010, p. 309)

As Kulvicki notes, this is because images can be quite reliably and intimately related to their content because they rely on the sources of perception available to examine the world as a whole. These resources are tried and true, which is what most of us are.

Another important recent contribution to the picture theory of the relation between thought and language is the conceptual/image metaphor theory that can be regarded as a key component of some contemporary semantic models in cognitive linguistics. As George Lakoff claims, conceptual metaphors are everyday expressions that have a conceptual domain in their background, in other words, a source domain that helps us understand more abstract phenomena that he calls target domain (Lakoff, 2008a, 2008b). This correspondence is done through simple notions we encounter in our everyday experience. Metaphors like this, he says, are not isolated linguistic tools with a decorative function, but rather enable humans to grab more complex concepts, and thus form mundane expressions that structure their knowledge (e.g., the "foundations of one's theory," the "building of arguments," etc.). Metaphor, in this approach, is therefore, primarily conceptual, and at a secondary level linguistic and visual. Metaphoric thinking, he says, the metaphorical understanding of situations of action, is an ability independent of language.

The simplest elements of narratives in everyday communicative situations are the conceptual relations that form when two basic bodily experiences are realized regularly and simultaneously. These components are named primary metaphors 
by Lakoff (2008a). They take action when we understand goals as goal destinations. Our everyday bodily experience is the basis for our empirical experiences that connect our realized goals (e.g., get a book) with the arrival to goal destinations (e.g., go to the library). The most basic components of the network of body metaphors are, therefore, primary metaphors that become elements of complex conceptual metaphors and that are born as a result of real interaction through the bodily experiences of the world. This is why we can see all our conceptual metaphors as results of embodied cognition. Lakoff and Johnson (1999) point out that the acquisition of simple metaphorical thinking takes place long before language acquisition; therefore, it is independent of language, and has an important role in the formation of grammatical forms. Primary metaphors based on everyday bodily experiences and complex conceptual metaphors formed as a combination of these thus play a key role in everyday meaning construction and in the organization of narrative structures that determine mundane communication. These metaphors can become the building blocks of narratives because they themselves constitute schematic event structures as conceptual representations of situations of action. Therefore, they facilitate the use of conventional narratives of mundane motives and their application in mundane situations, for example, in science, politics, or art. Event structure schemes in metaphors become elements of constants that have a key role in organizing everyday bodily and community experiences into scientific, political, and artistic narratives.

Since metaphors are based on a mental image, for the efficient application of a metaphor, we need an active contribution of mental pictures. As Nyíri points out, Lakoff and Johnson introduce the concept of image metaphor on the basis of this concept; they

on the one hand argue that our language and thinking are deeply and thoroughly metaphorical; and, on the other hand, that the source of those metaphors is the human body itself - its parts, postures, and movements. (Nyíri, 2003, p. 167)

Regarding the conceptualization of the relations between metaphors and mental pictures, the authors argue that this kind of metaphor is a cognitive pattern by which the words develop pictures that represent special, conventional knowledge. As Nyíri emphasizes, this theory highlights the pictorial nature of the whole of language which is rooted in our bodily experiences and the concrete-direct facilities of our environment, and, of course, the pictorial nature of all metaphorics (Nyíri, 2017).

Accordingly, if we accept the hypothesis about the pictorial nature of our cognition, we can find the account plausible that verbal utterances rich in pictures are not only enhancing the efficiency of communication but also contribute to the strengthening of interpersonal relationships in real communities. In other words, efforts to make human communication more efficient act as forces that shape and organize communities. We can safely state that pictures that go together with words also themselves become tools for the creation of communities. Nyíri's statement, however, raises a number of questions. One of these is the question of whether the newly born language for communication becomes pictorial only in the sense that we add pictures to the verbal, oral content in order to enhance efficiency of understanding. 
Do semantic changes that go hand in hand with the expansion of electronic communication make the words, phrases, sentences themselves "pictorial"? Are there semantic changes of this kind at all? If so, how can we describe them, and what effect do these have on our conceptual representations, on our thinking?

In order to suggest answers to these questions on the basis of Nyíri's argumentation, we must go back to the general description of the culture of communication that emerges as a result of the spreading of new types of media, namely to the notion that the new culture of communication using novel electronic devices-contrary to previous periods in the history of culture-is not characterized by the predominance of one type of technology, but rather by the gradual merging and mutual influence of linguistic usage relevant for one or the other technology. When literacy became predominant, taking the place of orality-based culture and thinking, and with the emergence of book-printing, a new language emerged, a language with distinct characteristics from that of oral language in terms of its semantic and logical system. Written language, therefore, took the place of orality in the transmission of information and knowledge, which, in the long run, created the distinct segregation of the linguistic characteristics of written and spoken language. This turn in the technology of communication so important in the history of culture did not only trigger the emergence of a new type of grammar but also changed the structure and content of our thinking and has modified our schemes of perception. Literacy, especially writing with letters from the alphabet and the printing business that grew from this, eventually enabled us to perceive the object of our thinking in a holistic way, and to designate a perspective in time and space. Silent writing and reading led to the creation of the private sector of the mind, the notion of a distinct subject with cognition. Interestingly, the experience of literacy led to the distinction of parts of speech such as nouns and verbs, to the concept of meaning, or to the problem of the definability of meaning. Therefore, literacy, has brought along a new world of epistemology, with a new conceptual and cognitive background. This powerful shift was powered by the unfolding of a new system of language strikingly different from orality. This new, analytical language, with the spread of literacy, gradually moved further and further from the characteristics of oral communication.

The appearance of electronic media and its increased use however changes the situation. Between the frameworks of this new orality emerging as a result of widespread electronic communication and that of secondary literacy, the abovementioned processes slow down and in fact, take opposite directions. The culture of communication where people gather and transmit their knowledge on the radio, television, and internet or with mobile phones integrating other forms of multimedia gradually moves in the direction of a dominance of a new medium that is characterized by the synthesis and nearing of the distinct languages of literacy and orality.

In the next part of this essay, I turn to the above-mentioned convergence of language forms and distinguish two levels of these. At the first level of the converging modalities, we see two basic forms of the synthesis of written and oral usage: the complete integration of vocalized language and pictures, and that of text and pictures. The first is mostly seen in radio- and television-based communication and is a communication technology known as secondary orality, by courtesy of Ong (1982), while the latter type is mostly found in the language of the internet also known as 
"netspeak," so named by Crystal (2004). Although each of these two forms build on different mechanisms of the interaction between pictures and language, both encourage the integration and convergence of the grammatical and semantic aspects of written and oral language use, and with that, they strengthen the spread of different registers and sociolects spoken by different layers and groups in society, as opposed to that of literary language.

The language of electronic communication building new forms of communities was developed on two different levels of this convergence. The first is manifested in a new type of orality present in the language we use in telephone conversations and on radio and television, that gained more and more importance in the process of everyday exchanges of information beside printed, written forms of language use. This new form of orality was the first unquestionable and clear sign of the birth of post-literate culture that rejects the dominance of literacy. Ong's secondary orality, the new form of media, therefore had a significant impact on our language and thinking (Ong, 1982, pp. 135-138). This undoubtedly earmarked the birth of a new language adapted to build new communities, a language that incorporated features of "primary orality" from the times before literacy, and those of literacy as well. This new medium requiring the convergence of orality and literacy has become the basis for the appearance of new communities and new forms of attachment in them; its use gradually enhanced the blurring of boundaries between virtual and physical communities.

While the emergence of secondary orality brought along the convergence of orality and literacy, at the other level of the convergence of the language of electronic communication, we see the emergence of a completely new language, due to this synthesis. With the widespread use of the internet and mobile communication, multimedia communication referred to as "hypermedia" by Michael Heim has become a key component of common talk, which, due to its pictorial linguistic nature, accelerates the convergence of orality-literacy and makes that blend the basis of a new linguistic structure (Heim, 1996, p. 2). This newly born language, however, is not simply a merged form of orality and literacy. This language is more than just a mixture of two ancient forms of communication; using Naomi Baron's metaphor, it is more than a "centaur" of orality and literacy (Baron, 2000, p. 248). This new form entails the existence of a new medium that enables the fast and efficient transmission of a great quantity of information through a new form of interaction between pictures, vocalizations, and written words. The language of communication mediatized by computers and mobile phones becomes a crucial tool in everyday communication and also acts as an engine for the convergence of orality and literacy in the form of a third medium, distinct from orality and traditional literacy. This new medium, referred to as Netspeak by Crystal in his comprehensive work entitled Language and the Internet, can become the basis for a new communication technology different from orality and literacy due to its multimedia-based features (Crystal, 2004).

The medium emerging in the framework of the internet and mobile communication is thus a language that determines common strategies of communication and with that, our expectations and imaginations concerning the functions of language, by combining the features of multimedia language transmitted by orality, literacy, and new technologies. We should not forget about secondary orality kept alive by 
radio, television, and telephone, which will not be replaced by Netspeak but rather enriched and completed with the new possibilities that Netspeak offers. Secondary orality brings along the ever-present interaction of picture and speech, while with Netspeak the continuous interaction of picture and text is observed. Therefore, the two different types of media are connected primarily by their pictorial nature. It is through this pictorial nature, their common ground, that this continuous interaction between secondary orality and Netspeak can take place in the matrix of a myriad of communication channels based on different technologies. This interaction points in the direction of the emergence of a language structure that represents a novel union of orality and literacy in the communicative instances of mundane human interaction.

This second level of the convergence of language forms facilitating the birth of new communities ensures the integration of speech, written language, and pictures in a very apparent and relevant way, from both the grammatical and semantic aspect. The simultaneous transmission of written, spoken, and pictorial language, where the three modalities continually complement each other, has become the cornerstone of everyday communication, and as such, naturally, has a striking impact on everyday language use. In the next part of this section, I reflect on the types of convergence of the different modalities of language use that enhance the reciprocal nature of the logic in the functions of pictorial language and orality in the practice of multimediabased communication, and that lead to unknown patterns of linguistic creativity in written and spoken language.

The iconic revolution changing the routine of everyday communication leads to the creation of a linguistic structure that combines visual and verbal tools in formal and semantic aspects. The various forms of software appearing in the last decades, with their endless graphical possibilities, generated a new type of visual culture that triggers the emergence of forms of a creativity yet unknown in everyday, mundane language use. Computers and mobile phone applications used today, offering technological conditions of easy picture imaging, ensure that pictorial communication becomes widespread and that we can combine linguistic, visual codes in a creative way in the world of pictures with increasing ease. MMS, for example, enables the mobile phone user to edit pictures, to paste text into their own pictures (photos, or drawings), and to forward these in the form of a text message. In the linguistic world of new technologies, creativity does not only play a role as an enjoyable experience in common talk but also ensures efficient communication. Complementing verbal content with pictures in the visual dimension contributes to the increased efficiency of everyday communication, where new tools of linguistic creativity are used.

The iconic revolution visible in the expansion of new communication technologies thus lead to a convergence in the different forms of language use, where the transmission of orality and iconic language intensifies and becomes a key element of common talk. This, of course, significantly increases the role of linguistic creativity in the practice of everyday communication encompassing multimedia-based exchanges of information. Probably, this observation motivates many contemporary thinkers to portray linguistic creativity as a phenomenon of everyday language use, and not as a privilege of humans endowed with extraordinary knowledge and skills (Tannen, 1989; Cook, 1997; Crystal, 1998; Carter, 2004; Maybin \& Swann, 2007). 
Creativity is a feature of language penetrating common talk, says Roland Carter in his book entitled Language and Creativity; in other words, it is "not only a distinct feature of extraordinary people, and an extraordinary feature of ordinary people" (Carter, 2004, p. 13). No wonder the notion of linguistic creativity gets novel interpretations and its ways of interpretation experience a sense of "democratization" in this novel framework of multimedia communication. With the spread of new communication technologies, language games, acronyms, humor, and picture-word combinations that are becoming increasingly popular encourage applied linguists to see everyday speakers of the language as creative designers of linguistic meaning.

The birth and spread of the new language of communication is, therefore, a result of a conscious decision by humans who have the necessary knowledge of the linguistic and conceptual elements of literacy, who believe that by using this type of language they can join the accelerating and global transmission of information more efficiently and can express themselves more clearly about common conceptual notions and emotions to the members of their local communities. The language of communication in today's electronic media, therefore, integrates features of oral and written language. This is the primary reason for the distinct, pictorial nature of this new type of language use, which, of course, exhibits important semantic and syntactic characteristics.

Among these, probably the most important is the increasing use of linguistic elements semantically acting as "umbrella terms": integrating several layers of conceptual connections from a wide range of associations, compressing these into "pictures" not analyzed at the conceptual level. The pictorial nature enhanced by the interaction of this secondary orality and Netspeak, however, does not simplify but rather further differentiates our linguistic trajectory, which therefore can, on the one hand, become a new tool for the mapping of new conceptual phenomena, while on the other hand speeding up the global transmission of information by enhancing the effects of semiotic globalization.

But where does the pictorial nature of these new forms of communication reside? What changes in grammar, lexicon, and semantics mirror the spreading of orality stemming from the interaction of Netspeak and secondary orality? Before answering these questions, we first need to clarify that whatever constitutes the medium of convergence of orality-literacy, be it secondary orality or Netspeak, the new linguistic forms represent a third type of usage, different from oral and written expression as well. Crystal also points this out; when defining Netspeak he emphasizes that, although Netspeak is a written language very similar to spoken language, we cannot claim that it is a type of spoken language, nor can it be identified with written language, because its core defining features incorporate the characteristics of both (Crystal, 2004, pp. 24-25). As mentioned above, Crystal does not consider Netspeak to be a simple sum of the features of written and spoken language, but rather sees it as a completely new medium; That is, he does not agree with authors who advocate that Netspeak is a "centaur"-type, hybrid mix of spoken and written language but, on the contrary, supports the views of thinkers who see Netspeak as a new type of language in its own right, that emerged from computer use, and that is distinctly different from written and spoken language. Authors favoring this approach include Marilyn Deegan, who believes that linguistic changes in connection with 
the distinctive features of electronic texts (such as plasticity, intertextuality, etc.) are combined with specific features of spoken and written languages, thus making Netspeak a "third medium" in its own right (Deegan, 2000). As Crystal puts it, "I have found clear signs of the emergence of a distinctive variety of language, with characteristics closely related to the properties of its technological context as well as to the intentions, activities, and (to some extent) personalities of the users" (Crystal, 2004, p. 225).

This also suggests, of course, that if new technologies are created that integrate the internet and other communicative situations, then a new form of convergence in linguistics takes place, to which new technologies ensure the necessary linguistic framework, just like we have seen in the case of the emergence of secondary orality, Netspeak, and the new orality from the interaction of these two.

The result of the convergence of languages leading to the birth of this new medium is that language becomes "pictorial," which brings along its own semantic and grammatical distinctive features. In terms of semantics, this newly emerging language becomes "pictorial" because its lexicon contains more and more elements of complex conceptual nature, whose semantic domain is not based on a conceptual connection defined as the result of mental reflection but encompasses a wide range of associations of conceptual connections not directly reflected on. In other words, a new metaphorical language is being created, that is destined to "reflect" the world by showing it in the form of pictures, to use the Wittgensteinian expression, rather than analyzing and dissecting it with more novel concepts and categories.

The convergence of forms of language use presented above leads to the birth of a new linguistic medium with a peculiar synthesis of conceptual and pictorial thinking. As for semantics, this recently emerging language can be regarded as a new kind of medium of communication, because its lexicon contains more and more elements of complex conceptual nature, whose semantic domain is not based on a conceptual connection defined as the result of mental reflection, but which encompasses a wide range of associations of conceptual connections not directly reflected on. In other words, a new metaphorical language is being created, that is destined to "show" the world by putting it into pictures, to use the Wittgensteinian expression, rather than analyzing and dissecting it with more novel concepts and categories. By using it, individuals communicating in this language want to "make others see" and "imagine" the world around us, rather than determine and analyze the conceptual connections at hand. The intention of the language user here is very similar to that of preachers, poets, and philosophers from the times before literacy, with one slight difference also emphasized by Ong: that this language emerging in the times of electronic communication is a result of a conscious decision (Ong, 1982, p. 136), with which humans in the era of secondary orality and Netspeak try to embed conceptual connections that have already been explored and mapped into an even more complex matrix of associations in a way to project and reveal the relationships and meaning connections with expressions of wide semantic domains, without breaking up complex associations. This process, of course, eventually leads to the simplification of grammatical structure, because the application of these expressions of complex semantic domains makes the use of more complicated, manifold complex sentential complements stemming from the conceptual analysis simply unnecessary. 
These new semantic features of the novel forms of orality have thus contributed to the formation of a community of shared information at a global scale, representing the core of globalization. Obviously, this process has been significantly accelerated by computer use, and especially by mobile phones with their multimedia applications and tools accessible to even more people. The triad of text, picture, and sound offers a fruitful ground for the above explained semantic changes and for the globalization of these changes. Multimedia communication, its pictures and sounds that can be understood very efficiently by everybody, significantly contributes to the amplification of semiotic globalization and to the birth of a sign system that can be interpreted universally. This system of signs on the verge of globalization, mostly composed of images, in the framework of a new type of orality, accelerates the spread of global linguistic effects that influence the languages of nations, i.e., the processes of semantic globalization.

\section{Conclusions}

Apparently, a new language for communication is emerging in front of our eyes, the description of which is still to come. One thing we know for sure, however: that global language barriers and semantic changes through the use of electronic media point in the direction of a linguistic galaxy that can contribute to the creation and strengthening of higher levels of human relationships. With the appearance of semantic fundamentals of the new orality, the mental and linguistic conditions are given for the members of information society belonging to different cultures and languages to become the winners of globalization smoothly and without experiencing conflicts of serious crises of values. As a result of these semantic changes, the core conceptual fundamentals of openness and trust in society are created in the linguistic cultures themselves, hence a new form of community consciousness emerges that ensures the cohesion of information society.

The concept of pictorial language as understood by Nyíri can thus lead us back to his concept on the transmission of speech, text, and picture that characterizes multimedia communication, and to his thoughts on the corollaries of social cohesion. We must point out, though, that the notion of pictorial language as introduced by Nyíri can only become a reliable element of theories on mental and linguistic processes in electronic communication if it gets further analyzed in semantic and philosophical aspects. This concept, just like Nyíri's several observations as well, have largely contributed to a new approach in which we can investigate the new technology of communication as a key component of our mental operations of knowledge and information processing, so that we can monitor what is happening to us while we cooperate by communicating with the given technology at hand. 
Funding Open access funding provided by University of Pécs. The author declares that he received no specific funding for this study.

\section{Declarations}

Conflict of interest The author declares that he has no conflict of interest.

Open Access This article is licensed under a Creative Commons Attribution 4.0 International License, which permits use, sharing, adaptation, distribution and reproduction in any medium or format, as long as you give appropriate credit to the original author(s) and the source, provide a link to the Creative Commons licence, and indicate if changes were made. The images or other third party material in this article are included in the article's Creative Commons licence, unless indicated otherwise in a credit line to the material. If material is not included in the article's Creative Commons licence and your intended use is not permitted by statutory regulation or exceeds the permitted use, you will need to obtain permission directly from the copyright holder. To view a copy of this licence, visit http://creativecommons.org/licen ses/by/4.0/.

\section{References}

Abell, C., \& Currie, G. (1999). Internal and external pictures. Philosophical Psychology, 12(4), 429-445.

Arnheim, R. (1969). Visual thinking. Berkeley, CA: University of California Press.

Baron, N. S. (2000). Alphabet to email: How Written English evolved and where it's heading. London, New York: Routledge.

Carter, R. (2004). Language and creativity: The art of common talk. London: Routledge.

Cook, G. (1997). Language play, language learning. English Language Teaching Journal, 48, 133-142.

Crystal, D. (2004). Language and the internet. Cambridge: Cambridge University Press.

Deegan, M. (2000). Introduction. In F. Condron \& M. Fraser \& S. Sutherland (Eds.): CTI (Computers in Teaching Initiative) Textual Studies: Guide to Digital Resources for the Humanities (pp. 1-12). Oxford: Oxford University Press.

Gombrich, E. (1972). The mask and the face: The perception of phy-siognomic likeness in life and art. In E. Gombrich \& J. Hochberg \& M. Black (Eds.): Art, Perception, and Reality (pp. 1-46). Baltimore: The Johns Hopkins University Press.

Heim, M. (1996). Virtual reality and the tea ceremony. Princeton, NJ: Princeton Architectural Press.

Kulvicki, J. (2010). Knowing with images: Medium and message. Philosophy of Science, 77(2), 295-313.

Lakoff, G. (2008a). The political mind: A cognitive scientist's guide to your brain and its politics. New York: Penguin Books.

Lakoff, G. (2008b). The neural theory of metaphor. In R. Gibbs (Ed.), The Cambridge handook of metaphor and thought (pp. 17-38). Cambridge: Cambridge University Press.

Lakoff, G., \& Turner, M. (1989). More than cool reason: a field guide to poetic metaphor. Chicago: The University of Chicago Press.

Lakoff, G., \& Johnson, M. (1999). Philosophy in the flesh: The embodied mind and its challenge to Western Thought. New York: Basic Books.

Maybin, J., \& Swann, J. (2007). Everyday creativity in language: Textuality, contextuality, and critique. Applied Linguistics, 28(4), 497-517.

Nyíri, K. (1992). Tradition and individuality: Philosophical essays. "Synthese Library”, Dordrecht: Kluwer

Nyíri, K. (1996/1997). Wittgenstein as a philosopher of secondary orality. Grazer Philosophische Studien, $52,45-57$

Nyíri, K. (2001). The picture theory of reason. In Rationality and Irrationality. In Brogaard, B. \& Smith, B. (Eds.) Rationality and irrationality (pp. 242-266). Vienna: Öbv \& hpt.

Nyíri, K. (2002). Pictures as instruments in the philosophy of Wittgenstein. In R. Haller \& K. Puhl (Eds.), Wittgenstein and the future of philosophy: A reassessment after 50 years (pp. 328-336). Vienna: Öbv \& hpt.

Nyíri, K. (2003). Pictorial meaning and mobile communication. In K. Nyíri (Ed.), Mobile communication: Essays on cognition and community (pp. 157-184). Vienna: Passagen Verlag. 
Nyíri, K. (2011). Image and metaphor in the philosophy of Wittgenstein. In: R. Heinrich et al., (Eds.) Image and imaging in philosophy, Science and the arts, Proceedings of the International Ludwig Wittgenstein Symposium, vol. 1 (pp. 109-129), Frankfurt: Ontos Verlag.

Nyíri, K. (2017). A képi reprezentáció a gondolkodás történetében s a képek kognitív szerepe (Pictorial representation in the history of thinking, and the cognitive role of pictures). In: G. Tolcsvai Nagy (Ed.) $A$ határok átlépése: Módszertani analógiák, közös problémák és elméleti párhuzamok a humán és természettudományos gondolkodásban (Crossing borders: Methodilogical analogies, common problems, and theoretical parallels in the humanities and natural sciences) (pp. 122-141), Budapest: Gondolat Kiadó.

Nyíri, K. (2019). Postscript: The Victory of the Pictorial Turn. In A. Benedek \& K. Nyíri (Eds.), Vision fulfilled: The victory of the pictorial turn (pp. 251-267). Hungarian Academy of Sciences / Budapest University of Technology and Economics.

Ong, W. J. (1982). Orality and literacy. The Technologizing of the Word. London, New York: Methuen.

Paivio, A. (1971). Imagery and verbal processes. New York: Holt, Rinehart, and Winston.

Price, H. H. (1953). Thinking and experience. London, New York: Hutchinson's Universal Library.

Tannen, D. (1989). Talking voices: Repetition, dialogue and imagery in conversational discourse. Cambridge: Cambridge University Press.

Westerhof, J. (2005). Logical relations between pictures. The Journal of Philosophy, 102(12), 603-623.

Publisher's Note Springer Nature remains neutral with regard to jurisdictional claims in published maps and institutional affiliations. 